\title{
SIMULATION STUDY OF A VEHICLE PRODUCTION LINE FOR PRODUCTIVITY IMPROVEMENT
}

\author{
M.F.F. Ab Rashid, N.M.Z. Nik Mohamed, A.N. Mohd Rose and K.Y. Kor \\ Faculty of Mechanical Engineering, University Malaysia Pahang \\ 26600 Pekan, Pahang, Malaysia \\ Phone : +609-424-6321; Fax : +609-424-6222 \\ Email: ffaisae@ump.edu.my
}

\begin{abstract}
This paper presents the study of a motorcycle frame production line in a particular company in Malaysia. Due to the high demand, the company needs to increase its production by at least $12 \%$ compared with current output. In order to improve productivity, the production-floor data was collected and simulated using the discrete event simulation approach. Later, a number of suggestions for improvement were simulated to identify the effect of the suggestions on productivity. In addition, cost analysis was also undertaken to identify the profit margin for a particular period of time for each suggestion. Simulation results indicate that there are three suggestions that are able to fulfill the $12 \%$ volume increment. In the short term, the suggestion to hire an assistant line leader will give instant effect to the profit. Meanwhile, for the medium term, Poka-yoke will give higher profit compared with the others, while in the long term, SOP (standard operating procedure) implementation will yield a better profit margin. In future, the simulation of a dynamic demand model for this product is suggested to cope with new trends in the market.
\end{abstract}

Keywords: Vehicle manufacturing; productivity improvement; simulation; discrete event simulation.

\section{INTRODUCTION}

Production flow and layout have always been of major concern in the production line. They directly affect the productivity of a manufacturing plant. Machines, raw materials, human labor, storage and more can be placed in different locations for best flow and productivity [1]. Various types of layout are applied today, namely process, product and fixed position layouts $[2,3]$. In fact, there are more layouts as some combine the best of many different layouts and form brand new ones, like the cellular layout. Discrete event simulation (DES) has been recognized as a powerful tool that is available to predict overall system performance, such as the throughput of a system [4]. In addition, it is also beneficial in identifying bottlenecks, evaluating proposed alternatives for eliminating bottlenecks, identifying under-utilized resources, and determining buffer sizes $[5,6]$. Simulation tools offer users the ability to investigate many diverse process systems for production plants, without spending large amounts of money on testing in real assembly plants [7]. One of DES software that widely used in industry is WITNESS simulation software. In the past, a number of case studies have been conducted by implementing DES techniques in order to enhance productivity. Paralikas used the DES technique to evaluate modular product design in the assembly system for 
automotive products [8] and found that the proposed system has high product flexibility but is exposed to product delay and low responsiveness to market fluctuations. On the other hand, Cagliano implemented a similar technique in the textile industry to predict warehouse performance when using different resources [9] and concluded that the operational cost can be reduced by outsourcing some of the operations [10].

In this study, a manufacturing company, ABC Metal Industries Sdn. Bhd., would like to increase their production for Model $\mathrm{Z}$ by at least $12 \%$ compared with current production due to higher demand. For this purpose, a number of suggestions will be made to achieve the target. The objective of this study is to analyze the suggestions that have been made for improvement to increase the productivity of the Model $\mathrm{Z}$ motorcycle in ABC Metal Industries Sdn. Bhd. The analysis includes the cost incurred and profits gained if a particular suggestion is implemented.

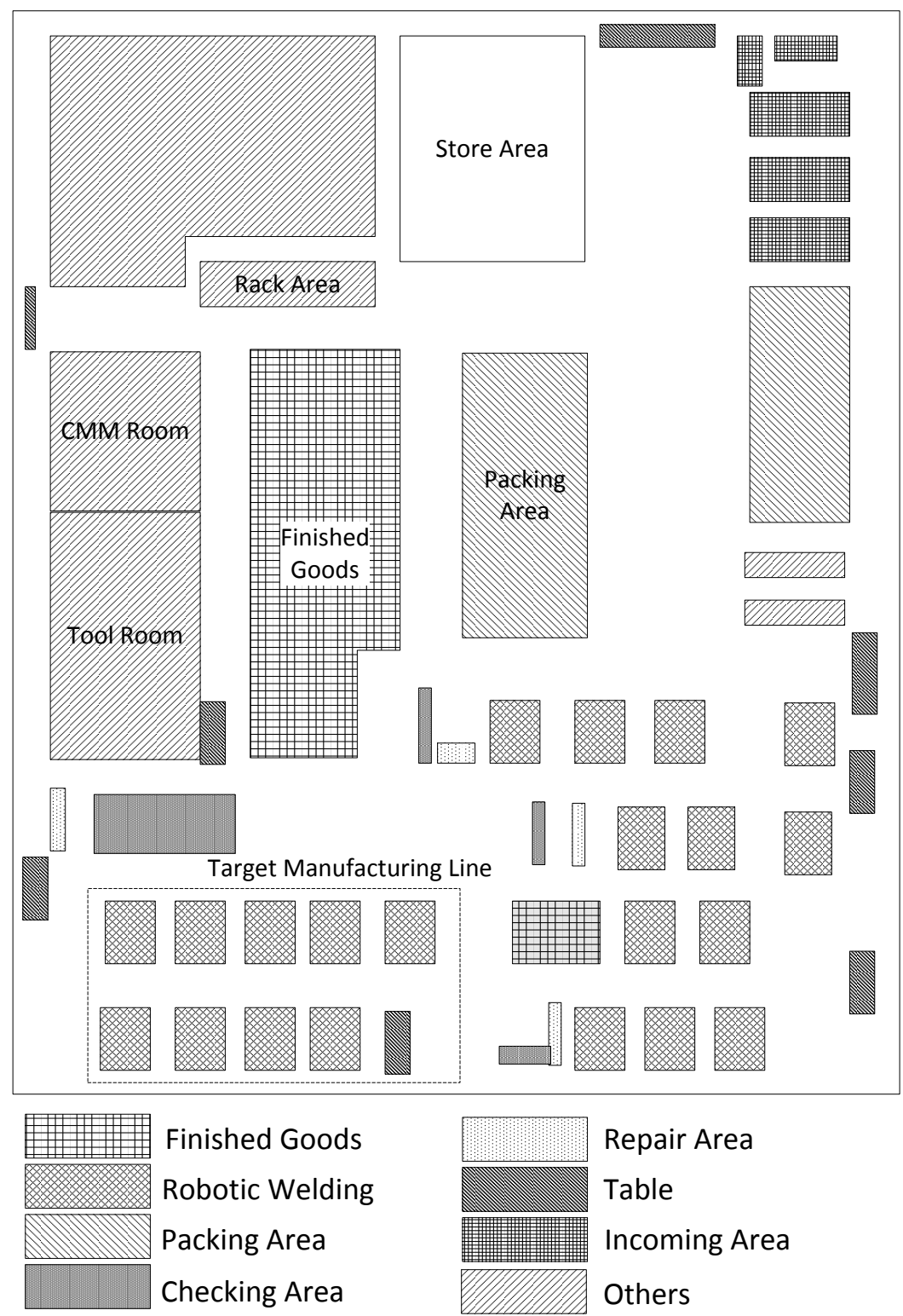

Figure 1. Layout of ABC Metal Industries Sdn. Bhd. 


\section{CASE STUDY}

The case selected for this study is that of ABC Metal Industries Sdn. Bhd., a subcontractor for a main motorcycle manufacturer in Malaysia. The company assembles motorcycle steel frames by welding. It has a total of 22 automated welding arms to carry out welding operations on seven different models of motorcycle. Figure 1 illustrates the factory layout of ABC Metal Industries Sdn. Bhd. It has a total of four production lines but we will only study one production line, as labelled in Figure 1, since this line is the largest and most complicated compared with the other three lines. This company has a relatively small layout, so in the target line, all the machines and buffers are next to each other. The manufacturing process of a motorcycle's steel frame involves many parts, ranging from the main tube to the battery brackets.

\section{SIMULATION MODEL}

The simulation model of the selected production line, with a total of 33 parts, 41 buffers, nine automated welding arms, nine welding operators and one line leader was built in WITNESS simulation software. Figure 2 presents the production layout in WITNESS. As originally, all the machines and buffers were next to each other, distance was not considered in this simulation. The simulation was allowed to run for five days with one shift. In the original production layout, all the automated welding arms were configured as multi-cycle machines where the processes were clearly listed with cycle times. The cycle times for all processes in the different machines were different based on their operations. Loading time was the time the welding operator took to load the parts onto the welding fixture and the assembly time was the time taken by the automated welding arm to weld the parts together.

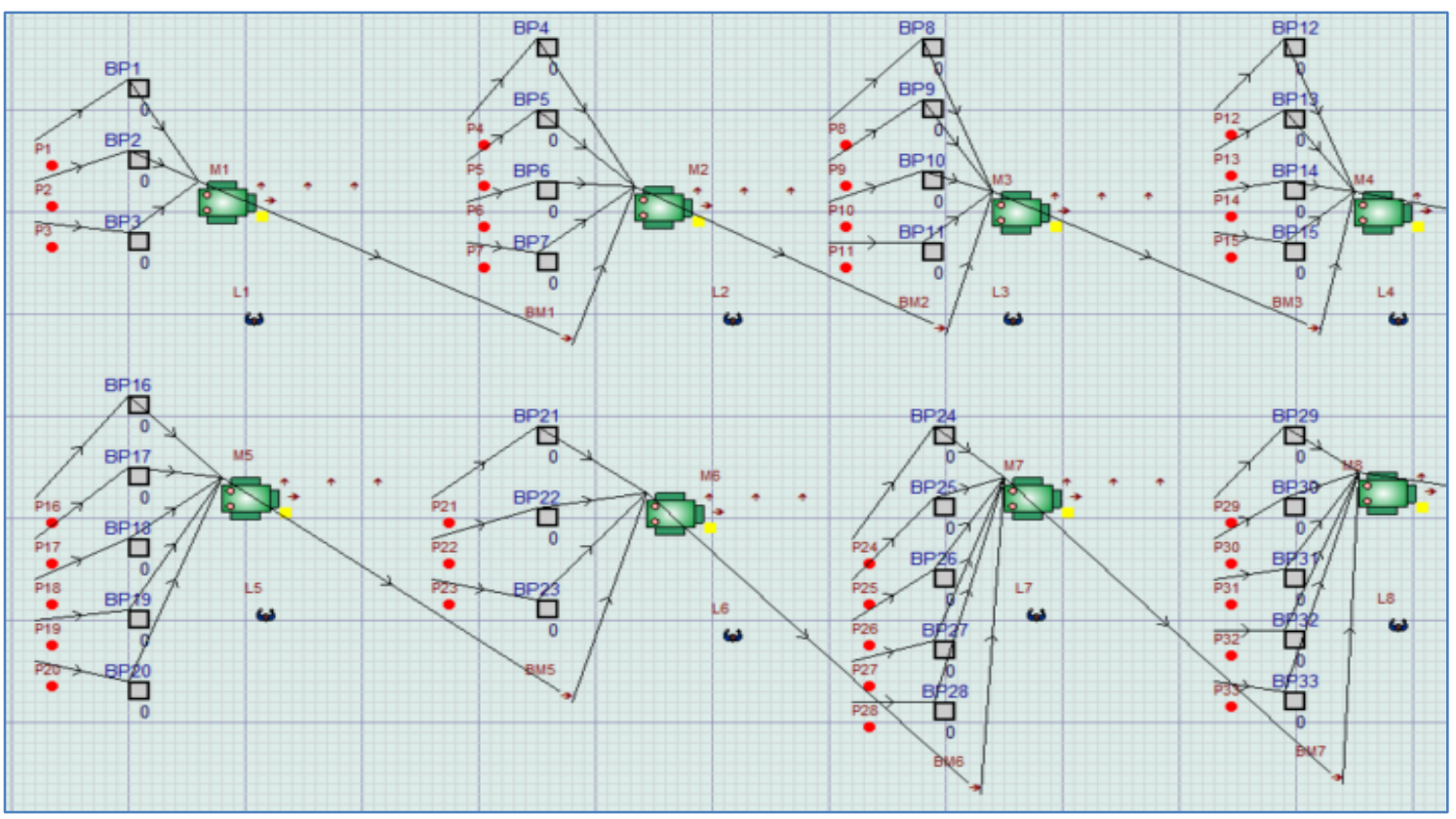

Figure 2. WITNESS simulation model for the default layout.

In addition, the machines were also set with breakdowns, consisting of machine breakdown, human error and spatter build up. Only the line leader had the skill and 
knowledge to repair the machines during breakdown. Furthermore, every machine was assigned one laborer to carry out the operations. The actual buffer size between machines is four. The machine ceases operation if the buffer is full.

\section{Suggestion for Improvement}

A total of five different suggestions were proposed to improve the default layout: (i) inprocess cleaning, (ii) preventive maintenance, (iii) hiring an assistant line leader, (iv) developing a standard operating procedure (SOP), and (v) Poka-yoke. All the improvements were carried out separately to determine the efficiency increment with only one factor in action.

\section{In-Process Cleaning}

In the welding operation, spatter build up causes the welding machine to break down or affects its performance. The spatter may block the welding nozzle and cause the filler metal to become stuck within the nozzle. This will lead to machine breakdown and repair is required. We simulated the setup to undertake nozzle cleaning for every 50 operations. This can prevent the accumulation of spatter at the welding nozzle. The time required to undertake such cleaning is far less than the time required to repair a broken down machine. For this suggestion, a nozzle cleaning setup of 60 seconds duration to be carried out by the welding operator was added to every machine. In addition, the breakdown due to spatter build up was removed from the breakdown list in the simulation model.

\section{Preventive Maintenance}

The preventive maintenance is increased by $50 \%$ to prevent breakdowns, i.e. it is undertaken every 50 operations rather than every 100 . In this case study, the company originally only conducted scheduled maintenance and calibration on welding fixtures every three months. Therefore, we recommended implementing preventive maintenance on both the automated welding arm and the welding fixture every two months to reduce breakdown. Contact tips, feed rolls, liners, feed pins, torches and other parts of the automated welding arm should be checked during the scheduled preventive maintenance. Furthermore, the dimensions of the welding fixtures should be checked during maintenance and calibration to ensure they are within the tolerance range.

\section{Hiring an Assistant Line Leader}

Given the situation that only the line leader has the skill and knowledge to repair a broken down machine, when multiple machines break down, they have to wait for the line leader to be available. For this reason, we simulated hiring an assistant line leader that also has the skill and knowledge to repair a broken down machine. In hiring the assistant line leader, new labor was added to the layout. The assistant line leader was assigned to repair every broken down machine. 


\section{Standard Operating Procedure}

An standard operating procedure (SOP) details the work processes to be conducted. In this case study, it provided clear instructions to the welding operators regarding the parts loading sequence of the automated welding arm to give maximum efficiency. Currently, the instructions in the welding bay focus more on safety and on how to use the welding machine. Without a clear set of instructions, an operator may load the parts in a different order in every operation. There is a sequence of parts loading that will consume minimal time. For this suggestion, every loading cycle for each machine was reduced by 20 seconds.

\section{Poka-yoke}

Poka-yoke is a technique that corrects mistakes as early as possible, sometimes before the occurrence of the mistake [11]. In this case study, small brackets to be welded to the motorcycle mainframe can be easily loaded in the wrong orientation. In addition, for some brackets, the left and right may look very similar but with some slight differences. Operators might mistakenly load them onto the welding fixture and cause the parts to be welded onto the wrong part of the motorcycle frame. Hence, we recommend corrective pins with special plates and stoppers to the existing welding fixtures. The implementation of Poka-yoke eliminates the breakdown caused by human error.

\section{RESULTS AND DISCUSSION}

The simulation result is measured based on a few indicators such as idle, busy, blocked, breakdown, repair awaiting labor and setup times. The busy and setup times are categorized as active times as the machines are in operation. Meanwhile, idle, blocked, breakdown and repair awaiting labor times are categorized as inactive times as the machines are not in operation. Blocked time is related to the breakdown of the previous machine. The buffer in this production line only holds up to four work-in-progress (WIP) units. So, when a machine breaks down and the buffer is full, the previous machine is blocked from operation.

Table 1 shows the simulation results of the default layout and the five suggestions for improvement for five working days per week. All the suggestion shows some improvement compared with the default layout in terms of the output per week. Based on the output, the suggestion to hire a new assistant line leader came out with the highest output, followed by introducing an SOP, Poka-yoke, preventive maintenance and, finally, the in-process cleaning suggestion. However, up to this stage, none of the suggestions considered the cost. From Table 1, the active time of the machines improved for all suggestions except for the implementation of SOP. For in-process cleaning, the nozzle cleaning action eliminated the breakdown caused by spatter build up at the nozzle. With this breakdown elimination, the production line suffered from fewer breakdowns and the time was used to manufacture more motorcycle frames. Preventive maintenance increased the number of operations before machine breakdown. This reduction in breakdowns increased the number of operations for every machine and laborer. 
Table 1. Simulation results of default and suggested layouts.

\begin{tabular}{|c|c|c|c|c|c|c|c|c|c|c|c|}
\hline \multirow{2}{*}{ Suggestion } & \multirow{2}{*}{$\begin{array}{c}\text { Time } \\
(\%)\end{array}$} & \multicolumn{9}{|c|}{ Machine } & \multirow{2}{*}{ Output (Unit) } \\
\hline & & M1 & M2 & M3 & M4 & M5 & M6 & M7 & M8 & M9 & \\
\hline \multirow{8}{*}{ 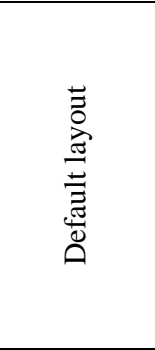 } & Idle & 0 & 0.8 & 1.5 & 8.21 & 0 & 2.68 & 1.24 & 2.58 & 29.04 & \\
\hline & Busy & 58.45 & 63.61 & 76.21 & 60.01 & 64.04 & 57.58 & 75.21 & 69.61 & 53.44 & \\
\hline & Blocked & 26.92 & 22.1 & 9.69 & 19.05 & 21.75 & 27.17 & 12.86 & 3.09 & 0 & \\
\hline & Broken & 11.21 & 8.45 & 8.18 & 8.08 & 9.49 & 7.98 & 7.1 & 12.79 & 11.31 & \\
\hline & Repair & 3.42 & 5.05 & 4.42 & 4.65 & 4.72 & 4.62 & 4.08 & 11.93 & 6.2 & \\
\hline & Setup & 0 & 0 & 0 & 0 & 0 & 0 & 0 & 0 & 0 & \\
\hline & Active & 58.45 & 63.61 & 76.21 & 60.01 & 64.04 & 57.58 & 75.21 & 69.61 & 53.44 & \\
\hline & Inactive & 41.55 & 36.4 & 23.79 & 39.99 & 35.96 & 42.45 & 25.28 & 30.39 & 46.55 & 741 \\
\hline \multirow{8}{*}{ 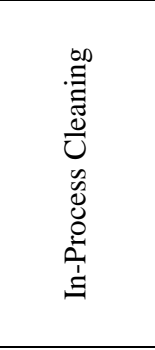 } & Idle & 0 & 1.48 & 1.34 & 9.61 & 0 & 3.05 & 1.14 & 3.38 & 28.67 & \\
\hline & Busy & 59.63 & 64.94 & 78.04 & 61.54 & 65.24 & 58.8 & 76.84 & 70.91 & 54.47 & \\
\hline & Blocked & 24.1 & 20.52 & 7.56 & 16.02 & 20.46 & 25.87 & 11.67 & 2.96 & 0 & \\
\hline & Broken & 10 & 7.27 & 6.57 & 6.87 & 8.48 & 6.77 & 6.16 & 11.52 & 10.35 & \\
\hline & Repair & 5.62 & 5.14 & 5.85 & 5.33 & 5.18 & 4.87 & 3.54 & 10.58 & 5.86 & \\
\hline & Setup & 0.65 & 0.65 & 0.65 & 0.65 & 0.65 & 0.65 & 0.65 & 0.65 & 0.65 & \\
\hline & Active & 60.28 & 65.59 & 78.69 & 62.19 & 65.89 & 59.45 & 77.49 & 71.56 & 55.12 & \\
\hline & Inactive & 39.72 & 34.41 & 21.32 & 37.83 & 34.12 & 40.56 & 22.51 & 28.44 & 44.88 & 756 \\
\hline \multirow{8}{*}{ 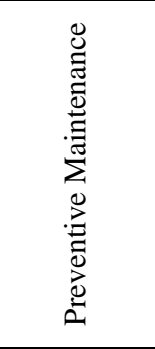 } & Idle & 0 & 0.74 & 1.79 & 11.81 & 0 & 1.63 & 1.49 & 3.55 & 25.65 & \\
\hline & Busy & 62.68 & 68.3 & 81.89 & 64.57 & 68.49 & 61.62 & 80.56 & 74.45 & 57.14 & \\
\hline & Blocked & 22.92 & 18.73 & 4.87 & 11.83 & 17.88 & 25.55 & 7.42 & 3.18 & 0 & \\
\hline & Broken & 10.71 & 8.06 & 7.48 & 7.81 & 9.12 & 7.27 & 6.4 & 12.63 & 11.14 & \\
\hline & Repair & 3.7 & 4.17 & 3.97 & 3.98 & 4.51 & 3.92 & 4.13 & 6.19 & 6.07 & \\
\hline & Setup & 0 & 0 & 0 & 0 & 0 & 0 & 0 & 0 & 0 & \\
\hline & Active & 62.68 & 68.3 & 81.89 & 64.57 & 68.49 & 61.62 & 80.56 & 74.45 & 57.14 & \\
\hline & Inactive & 37.33 & 31.7 & 18.11 & 35.43 & 31.51 & 38.37 & 19.44 & 25.55 & 42.86 & 793 \\
\hline \multirow{8}{*}{ 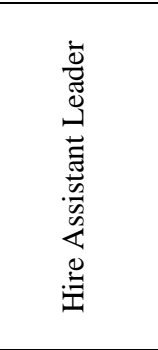 } & Idle & 0 & 0.23 & 0.54 & 11.57 & 0 & 1.65 & 0.26 & 1.61 & 23.74 & \\
\hline & Busy & 68.15 & 74.24 & 89.06 & 70.06 & 74.46 & 66.99 & 87.63 & 80.78 & 62.11 & \\
\hline & Blocked & 18.01 & 15.07 & 0.9 & 7.97 & 12.8 & 21.41 & 3.79 & 0.87 & 0 & \\
\hline & Broken & 12.76 & 9.8 & 9.36 & 9.38 & 11 & 9.02 & 7.95 & 14.88 & 13.27 & \\
\hline & Repair & 1.08 & 0.65 & 0.14 & 1.02 & 1.74 & 0.92 & 0.37 & 1.85 & 0.89 & \\
\hline & Setup & 0 & 0 & 0 & 0 & 0 & 0 & 0 & 0 & 0 & \\
\hline & Active & 68.15 & 74.24 & 89.06 & 70.06 & 74.46 & 66.99 & 87.63 & 80.78 & 62.11 & \\
\hline & Inactive & 31.85 & 25.75 & 10.94 & 29.94 & 25.54 & 33 & 12.37 & 19.21 & 37.9 & 862 \\
\hline \multirow{8}{*}{ 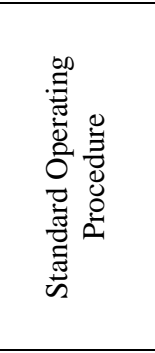 } & Idle & 0 & 4.64 & 3.95 & 14.04 & 0 & 3.21 & 2.8 & 6.37 & 30.27 & \\
\hline & Busy & 43.99 & 50.15 & 64.86 & 46.06 & 50.14 & 42.94 & 63.48 & 56.73 & 46.94 & \\
\hline & Blocked & 34.04 & 26.68 & 15.07 & 22.34 & 32.43 & 38.73 & 20.39 & 7.6 & 0 & \\
\hline & Broken & 12.96 & 9.8 & 9.02 & 9.37 & 11.18 & 9.02 & 7.81 & 14.44 & 13.06 & \\
\hline & Repair & 9 & 8.73 & 7.09 & 8.19 & 6.25 & 6.1 & 5.51 & 14.86 & 9.73 & \\
\hline & Setup & 0 & 0 & 0 & 0 & 0 & 0 & 0 & 0 & 0 & \\
\hline & Active & 43.99 & 50.15 & 64.86 & 46.06 & 50.14 & 42.94 & 63.48 & 56.73 & 46.94 & \\
\hline & Inactive & 56 & 49.85 & 35.13 & 53.94 & 49.86 & 57.06 & 36.51 & 43.27 & 53.06 & 850 \\
\hline \multirow{8}{*}{ 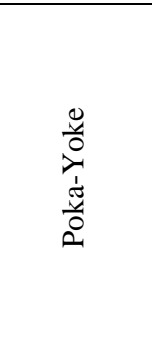 } & Idle & 0 & 0.83 & 0.76 & 12.9 & 0 & 1.98 & 1.38 & 4.36 & 26.74 & \\
\hline & Busy & 65.9 & 72.21 & 86.8 & 68.44 & 72.37 & 65.4 & 85.84 & 79.19 & 60.96 & \\
\hline & Blocked & 22.56 & 17.77 & 2.97 & 11.27 & 17.7 & 24.25 & 4.85 & 1.88 & 0 & \\
\hline & Broken & 9.08 & 7.37 & 7 & 6.63 & 8.15 & 6.73 & 6.33 & 9.6 & 9.29 & \\
\hline & Repair & 2.45 & 1.82 & 2.47 & 0.75 & 1.78 & 1.63 & 1.6 & 4.97 & 3 & \\
\hline & Setup & 0 & 0 & 0 & 0 & 0 & 0 & 0 & 0 & 0 & \\
\hline & Active & 65.9 & 72.21 & 86.8 & 68.44 & 72.37 & 65.4 & 85.84 & 79.19 & 60.96 & \\
\hline & Inactive & 34.09 & 27.79 & 13.2 & 31.55 & 27.63 & 34.59 & 14.16 & 20.81 & 39.03 & 846 \\
\hline
\end{tabular}


Hiring an assistant line leader significantly reduced the repair waiting time during breakdowns in that with multiple machine breakdowns at the same time and a single line leader, two machines cannot be repaired at the same time and having an assistant line leader can reduce the repair waiting time and the machine can operate again within a shorter period. In the SOP, the cycle time for loading was reduced, so each machine required less time to complete one full cycle. However, the percentage of breakdowns remains the same, resulting in higher blocked time. The implementation of the Poka-yoke concept on the welding fixtures helped to reduce breakdowns caused by human error. Therefore, it showed some improvement in terms of active time and the output number.

\section{COST ANALYSIS}

For every shipped motorcycle frame, ABC Metal Industries Sdn. Bhd. earns RM20 net profit. In this section, we will analyze the costs of implementing the suggestions, and then compare them with the sales volume. However, overhead and administrative costs are not considered. As the layout was simulated for five working days, the total output was multiplied by four weeks, assuming 20 working days for every month. The inprocess cleaning of the welding nozzle requires no extra cost, other than the compressed air for the operator to clean the nozzle. The amount of compressed air used in this process is insignificant compared to the total amount of compressed air used in the whole factory. Hence, it is assumed that this improvement does not require additional investment. Preventive maintenance required investment additional to the originally scheduled maintenance and calibration. Hence, the cost for preventive maintenance was estimated as in Table 2.

Table 2. Cost estimation for preventive maintenance.

\begin{tabular}{lcc}
\hline Item & Unit & Cost (RM) \\
\hline Automated Welding Arm-OTC & & \\
$\quad$ 1. Contact tip & 9 & 180 \\
2. Torch insulation & 4 & 120 \\
3. Nozzle & 5 & 100 \\
$\quad$ 4. Cable & 3 & 180 \\
$\quad$ 5. Feed rolls & 5 & 100 \\
$\quad$ 6. Torch & 2 & 150 \\
Welding Fixture & & \\
$\quad$ 1. Holding plates & 15 & 150 \\
$\quad$ 2. Compressed air hose & 9 & 45 \\
$\quad$ 3. Clamps & 4 & 60 \\
Repair tools and cost & & 300 \\
Lubrication oil & & 200 \\
Cleaning agent & & 150 \\
Miscellaneous & & 200 \\
\hline TOTAL & & 1785 \\
\hline
\end{tabular}

Since the recommended maintenance and calibration session is once every two months, the estimated additional investment in maintenance and calibration for each month is RM892.50. In hiring an assistant line leader, the company has to pay 
additional labor costs of RM1200 per month. Considering other employer benefits, such as the Social Safety Organization (SOCSO), Employees Provident Fund (EPF) and other miscellaneous beneficial costs, the total cost per month is RM1700. Developing an SOP will require extensive study of the production line by the production engineer. It will involve one-off costs such as training, process documentation and labor awareness. The cost of this suggestion is estimated at RM6000, the largest portion of which is for training. To implement Poka-yoke, the company has to invest in the one-off cost of improving the existing welding fixture. The estimated cost for implementing Poka-yoke for this manufacturing line is as in Table 3.

Table 3. Cost estimation for Poka-yoke implementation.

\begin{tabular}{lcc}
\hline Item & Unit & Cost (RM) \\
\hline Pin & 30 & 60 \\
Spring-loaded pin & 20 & 80 \\
Stopper & 20 & 50 \\
Plate & 30 & 180 \\
Installing tool and cost & & 400 \\
\hline TOTAL & & 770 \\
\hline
\end{tabular}

Based on the recommendation and estimated cost, Table 4 summarizes the net profit for each of the recommendations for one working month. Since the simulation results in Table 4 show the output per week, the number will be multiplied by 4 weeks to calculate the output for a month. $N_{s}$ represents the output for a particular improvement suggestion, while $n_{d}$ is the output from the default layout. The cost annotated with an asterisk is the one-off cost. The net profits per year for the first three suggestions were simply calculated by multiplying the net profit per month $\left(s_{n}\right)$ by 12 months. For the last two suggestions, the net profit per year is calculated by deducting the cost from the total gross profit for 12 months.

Table 4. Summary of the costs and profits.

\begin{tabular}{lccccc}
\hline Suggestion & $\begin{array}{c}\text { Improved } \\
\text { unit, } n_{i} \\
\left(n_{s}-n_{d}\right) \times 4\end{array}$ & $\begin{array}{c}\text { Gross } \\
\text { profit, } s_{g} \\
n_{i} \times \mathrm{RM} 20\end{array}$ & $\begin{array}{c}\text { Cost, } \\
c_{i}\end{array}$ & $\begin{array}{c}\text { Net profit, } \\
s_{n} \\
s_{g}-c_{i}\end{array}$ & $\begin{array}{c}\text { Net } \\
\text { profit/year }\end{array}$ \\
\hline $\begin{array}{l}\text { In-process cleaning } \\
\begin{array}{l}\text { Preventive } \\
\text { maintenance }\end{array}\end{array}$ & 60 & 1200 & 0 & 1200 & 14,400 \\
$\begin{array}{l}\text { Hiring assistant line } \\
\text { leader }\end{array}$ & 208 & 4160 & 892.50 & 3267.50 & 39,210 \\
$\begin{array}{l}\text { Standard Operating } \\
\text { Procedure }\end{array}$ & 484 & 9680 & 1700 & 7980 & 95,760 \\
Poka-Yoke & 436 & 8720 & $6000^{*}$ & 2720 & 98,640 \\
\hline
\end{tabular}

*One-off cost

Based on Table 4, there are three suggestions that are predicted to fulfill the required improvement and yield high profit margins. These are to hire a new assistant line leader (16.3\% improvement), introduce the SOP (14.7\% improvement) and 
implement the Poka-yoke concept (14.2\% improvement). Hiring the assistant line leader led to the highest output and also the highest net profit for the first month. Meanwhile, SOP implementation required a relatively large amount of cost, but it was a one-off investment. The company will experience lower profit for the first month, but in the long term, this suggestion will give better profit compared with hiring an assistant line leader. On the other hand, the Poka-yoke implementation came out with the highest net profit for the first year since it results in reasonably good output with a small one-off investment. Although this suggestion is predicted to give the highest profit for the first year, in the long term, SOP implementation will overtake the profit margin after 14 months of implementation.

\section{CONCLUSIONS}

This paper presents a case study on increasing productivity in a motorcycle-frame production line. Five suggestions were made and these were simulated using the DES technique to identify the effects of the changes on the production line. Three out of the five suggestions were identified to meet the $12 \%$ production improvement. In summary, the selection of the suggestion to be implemented will be based on its sustainability. In the short term, the suggestion to hire an assistant line leader will have an instant effect on the profit. In the medium term, Poka-yoke will give higher profit compared with the others, while for the long term, SOP implementation will yield the best profit margin. In the future, simulation of dynamic demand is proposed to overcome unstable demand for the studied product.

\section{ACKNOWLEDGMENTS}

The authors would like to acknowledge Universiti Malaysia Pahang for funding this study by a research grant under RDU1303113.

\section{REFERENCES}

[1] Sana SS. Preventive maintenance and optimal buffer inventory for products sold with warranty in an imperfect production system. International Journal of Production Research. 2012;50:6763-6774.

[2] Hasan MA, Sarkis J, Shankar R. Agility and production flow layouts: An analytical decision analysis. Computers \& Industrial Engineering. 2012;62:898907.

[3] Andrew-Munot M, Ibrahim R. Remanufacturing Process and Its Challenges. Journal of Mechanical Engineering and Sciences. 2013;4:488-495.

[4] Tako AA, Robinson S. The application of discrete event simulation and system dynamics in the logistics and supply chain context. Decision Support Systems. 2012;52:802-815.

[5] Feng SW, Zhang J, Ding SC. Simulation Analysis of Production Control Methods in Manufacturing Systems. Advanced Materials Research. 2012;490495:1704-1708.

[6] Civcisa G, Rudnevs J, Grislis A. Quality Management System in Small and Medium Mechanical Engineering Enterprises in Latvia. International Journal of Automotive \& Mechanical Engineering. 2014;10:1928-1934. 
[7] Chramcov B, Beran P. A simulation approach to achieving more efficient production systems. International Journal of Mathematics and Computers in SImulation. 2011;5:299-309.

[8] Paralikas J, Fysikopoulos A, Pandremenos J, Chryssolouris G. Product modularity and assembly systems: An automotive case study. CIRP Annals Manufacturing Technology. 2011;60:165-168.

[9] Corinna Cagliano A, DeMarco A, Rafele C, Volpe S. Using system dynamics in warehouse management: a fast-fashion case study. Journal of Manufacturing Technology Management. 2011;22:171-188.

[10] Rose A, Deros BM, Rahman MA. A Study on Lean Manufacturing Implementation in Malaysian Automotive Component Industry. and Authors Page. 2013;8:1467-1476.

[11] Koichi Murata KW, Akihiro Watanabe, Hiroshi Katayama. Analysis on Integrals of Lean Module Technologies-The Cases of Visual Management, Poka-Yoke and Karakuri Technologies. Research in Electronic Commerce Frontiers. 2013;1. 